\title{
EVOLUÇÃO DOS PALEOCANAIS DA REGIÃO COSTEIRA DO RIO GRANDE DO SUL DURANTE O QUATERNÁRIO TARDIO
}

\author{
WESCHENFELDER, J. ${ }^{1}$ \& CORRÊA, I. C. S. ${ }^{1 *}$ \\ 1. Centro de Estudos de Geologia Costeira e Oceânica do Instituto de Geociências da UFRGS \\ *Corresponding author: iran.correa@ufrgs.br
}

\begin{abstract}
Weschenfelder, J. \& Corrêa, I. C. S. (2018). Evolução dos Paleocanais da região costeira do Rio Grande do Sul durante o Quartenário Tardio. Brazil. Braz. J. Aquat. Sci. Technol. 22(1). eISSN 1983-9057. DOI: 12999/bjast.v22n1. Reflection seismic studies have revealed paleochannels dissecting the Rio Grande do Sul coastal plain before the installation of the actual, low-relief and gently undulating landscape. Two distinct paleochannels systems were established in the Patos lagoon area: a) the "Late Pleistocene", buried by a package around $12 \mathrm{~m}$ thick of coastal sand and mud; b) the "Late Pleistocene/Holocene", blanked by a thin package of lagoonal mud (up to $2 \mathrm{~m}$ ). The channel filling of the younger system is Holocene, as indicated by radiocarbon dating. It is related to the last marine regression of the Late Pleistocene, corresponding to the oxygen isotope stage 2. Thus, the incision and filling of the older system is related to the previous regressive-transgressive event, corresponding to the oxygen isotope stages $6-5$. The paleodrainage paths from seismic were connected with those previously recognized in the adjacent continental shelf and slope. Landwards, the paleodrainages are linked with the present courses of the Camaquã and Jacuí rivers.
\end{abstract}

Key Words: Paleochannel; Paleogeography; Coastal Plain.

\section{INTRODUCTION}

A região costeira do Rio Grande do Sul apresenta escassos estudos dedicados à caracterização sísmica dos pacotes sedimentares. Em alguns trabaIhos, elementos arquiteturais da plataforma continental do Rio Grande do Sul têm sido interpretados como paleocanais que se desenvolveram em consequência dos eventos regressivos do nível do mar durante o Quaternário. Esses canais foram posteriormente afogados e preenchidos durante os eventos transgressivos subsequentes (Corrêa, 1996; Abreu \& Calliari, 2005). Estudos de Toldo et al. $(2000,2006)$ indicam a presença de paleocanais em ecogramas de $7 \mathrm{kHz}$ no subfundo da Lagoa dos Patos. Levantamento de sísmica de reflexão de alta resolução realizado por Corrêa et al. (2004) revelaram ainda a presença de estruturas de barreira no subfundo do canal de acesso à Lagoa dos Patos, em Rio Grande.

Estudos mais recentes, através de dados de sísmica de reflexão de alta resolução, identificaram importantes sistemas de paleodrenagens que dissecaram a planície costeira média e norte do estado do Rio Grande do Sul durante o período Quaternário (Weschenfelder et al., 2005; 2008; 2014). São sistemas de dissecação costeiros que tiveram um papel importante na arquitetura deposicional, distribuição das fácies sedimentares e geração de espaço de acomodação do prisma costeiro da bacia marginal de Pelotas. Registros sísmicos de $3,5 \mathrm{kHz}$ permitiram ainda identificar, de forma pioneira, importantes acumulações de gás raso no substrato da Lagoa dos Patos, ocorrentes principalmente na forma de "bolsões de gás" e "gás disseminado", além de outros elementos sísmicos relacionados à presença de gás (Weschenfelder et al., 2006).

Este trabalho aborda os sistemas de paleocanais, delineados por superfícies de descontinuidade sismo-deposicional, revelados em registros de sísmica de reflexão de alta resolução do substrato da Lagoa dos Patos. O estudo aborda ainda a cronologia dos eventos de dissecação do relevo e a evolução paleogeográfica da região costeira.

\section{MATERIAS E MÉTODOS}

\section{Área de Estudo}

Á área de estudo compreende parte da planície costeira e da plataforma continental do Rio Grande do Sul, entre as latitudes de $30^{\circ} 00^{\prime} \mathrm{S}$ a $32^{\circ} 20^{\prime} \mathrm{S}$ e as longitudes de $50^{\circ} 00^{\prime} \mathrm{O}$ a $52^{\circ} 00^{\prime} \mathrm{O}$ (Figura 1 ).

A plataforma continental apresenta-se homogênea, com superfície morfológica suave, gradiente muito baixo $(1,3-1,4 \mathrm{~m} / \mathrm{km})$ e largura média de $125 \mathrm{~km}$. A planície costeira é uma ampla área plana de terras baixas, com superfície aproximada de $33.000 \mathrm{~km}^{2}$, e em grande parte ocupada por um sistema de lagoas costeiras. 
A Lagoa dos Patos apresenta uma fisiografia marcante na região costeira do Rio Grande do Sul. É uma laguna extensa, com área aproximada de $10.000 \mathrm{~km} 2$, profundidade média de $6 \mathrm{~m}$ e abrigada por um cordão arenoso do ambiente dominado por ondas do oceano adjacente. A formação da Lagoa dos Patos foi propiciada pelos eventos de variação do nível do mar do final do Quaternário. Os depósitos sedimentares que delimitam a laguna têm sido relacionados aos quatro últimos eventos transgressivoregressivos, responsáveis pela formação de quatro sistemas deposicionais do tipo laguna-barreira: os sistemas I (mais antigo), II e III foram formados no Pleistoceno Superior, enquanto o sistema IV está em formação desde o inicio do Holoceno (Tomazelli \& Villwock, 2000).

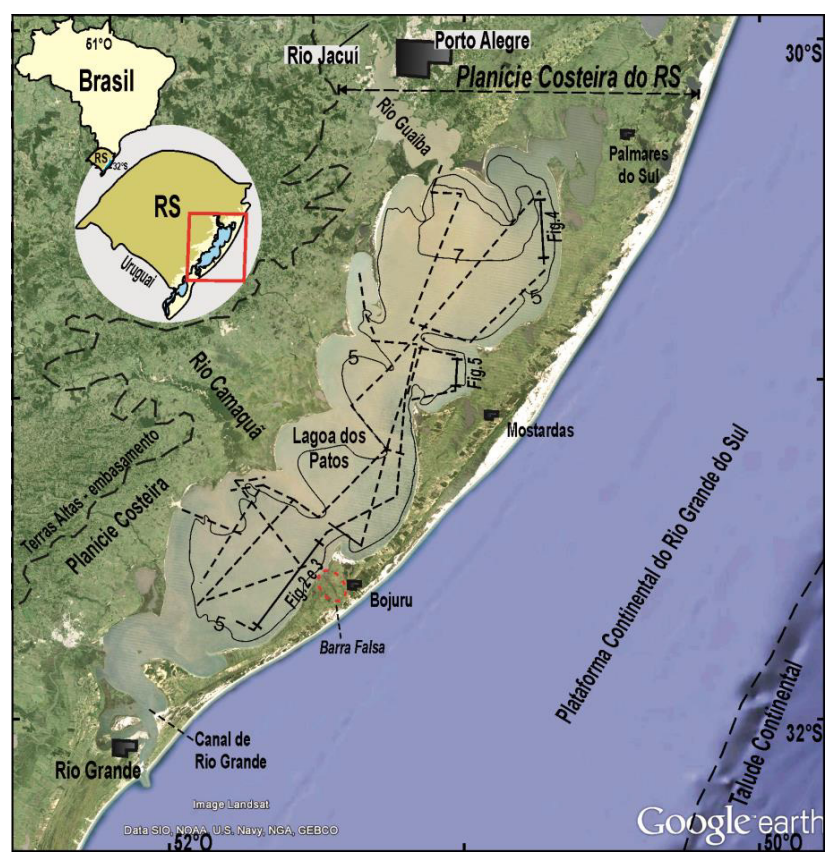

Figura 1 - Localização da área de estudo e dos perfis de sísmica de reflexão de 3,5 e $7 \mathrm{kHz}$ no interior Lagoa dos Patos, na planície costeira do Rio Grande do Sul.

\section{Metodologia}

Este artigo tem como base principal a análise dos elementos arquiteturais identificados nos registros sísmicos de alta resolução na Lagoa dos Patos.

Foram utilizados, aproximadamente, $1000 \mathrm{~km}$ de perfis de sísmica de reflexão de alta frequência (3,5 kHz) e resolução, obtidos no interior da Lagoa dos Patos (Fig. 1) a bordo da Lancha Oceanográfica LARUS, da FURG. A rota e o posicionamento dos perfis foram definidos por um sistema de posicionamento global por satélite (DGPS). Para a aquisição dos registros de sísmica de reflexão foi utilizado um perfilador de subsuperfície GeoAcoustics, composto por transmissor Geopulse (5430A), receptor Geopulse (5210A), transdutor Geopulse (132B), unidade de processamento (GeoPro) e software de aquisição sísmica (Sonarwiz). O transdutor foi fixado no casco da embarcação, servindo então simultaneamente como emissor e receptor do sinal acústico. Os dados de sísmica de reflexão foram armazenados no formato digital SEG-Y. Registros sísmicos de reflexão de $7 \mathrm{kHz}$, caracterizados nos trabalhos de Toldo (1994) e Toldo et al. (2000; 2006), são também analisados neste trabalho em complemento aos registros de $3,5 \mathrm{kHz}$.

O reconhecimento e o mapeamento das sequências e fácies sísmicas do substrato da Lagoa dos Patos, assim como dos diversos elementos arquiteturais a elas associados, tiveram como base a análise da configuração interna dos refletores, a terminação lateral das superfícies sísmicas e a geometria externa dos pacotes, em concordância com as linhas gerais estabelecidas pela sismoestratigrafia (Mitchum et al., 1977). A profundidade dos refletores sísmicos foi inferida com base a uma velocidade média de deslocamento do sinal acústico de $1650 \mathrm{~m} / \mathrm{s}$ nos sedimentos e de $1500 \mathrm{~m} / \mathrm{s}$ na água.

\section{RESULTADOS E DISCUSSÃO}

A análise sismoestratigráfica é uma abordagem metodológica que permite uma interpretação geológica sistemática dos registros de sísmica de reflexão, fornecendo informações importantes à cerca dos processos de sedimentação, variações do nível do mar, paleotopografia, superfícies erosivas e de descontinuidades sismo-deposicionais, entre outras. Em ambientes costeiros, descontinuidades sísmicas marcantes podem indicar superfícies erosivas vinculadas a eventos significativos de rebaixamento do nível do mar (nível de base), as quais marcam os limites das sequências sismo-deposicionais.

Estudos sismo-estratigráficos conduzidos por Weschenfelder (2005) e Weschenfelder et al. (2005) definiram três sequências sísmicas, e suas fácies constituintes, em registros de $3,5 \mathrm{kHz}$ na Lagoa dos Patos (Figura 2a e b). Fortes discordâncias, marcadas por superfícies de truncamentos dos refletores sísmicos, orientaram no reconhecimento desses pacotes sismo-deposicionais. Segundo esses autores, o limite entre as sequências S2 e S3 foi formado durante o último grande evento regressivo do final do Pleistoceno; o limite da sequência S2-S3 corresponderia, portanto, ao evento regressivo imediatamente anterior, do Pleistoceno (Figura 3). 


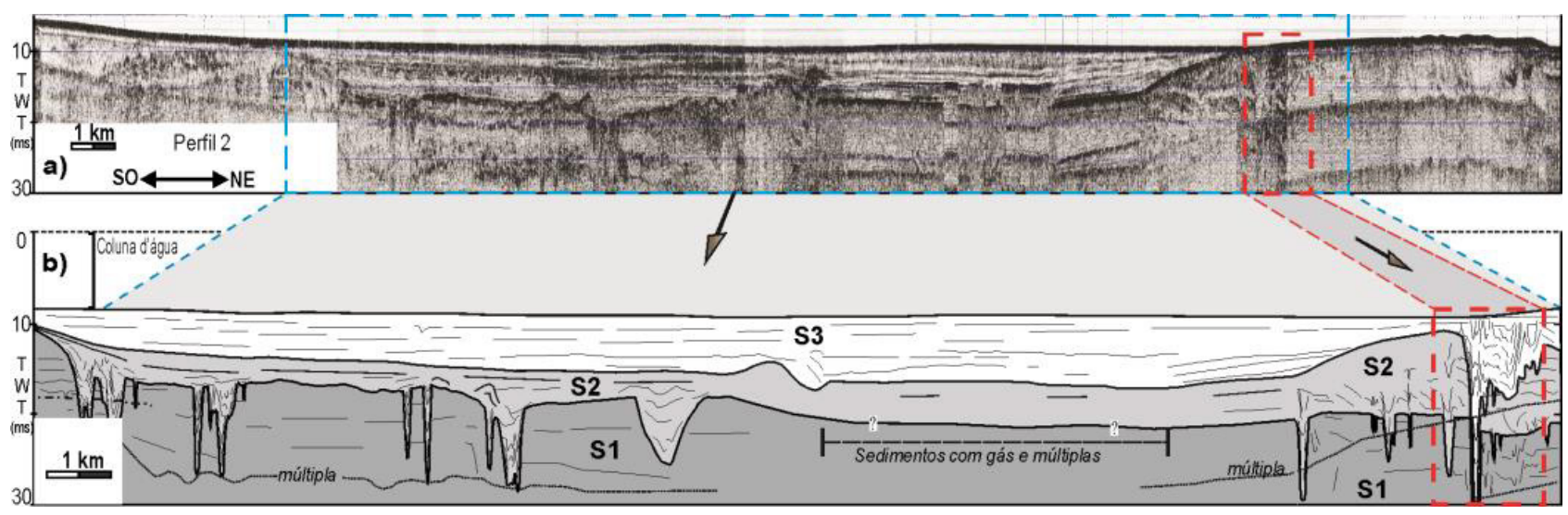

Figura 2. Registro sísmico do setor leste da Lagoa dos Patos (ver Figura 1) mostrando em destaque a drenagem pretérita do rio Camaquã (a) e os elementos arquiteturais sismo-deposicionais e descontinuidades e sequências sísmicas S1, S2 e S3 (b). Profundidade em tempo de ida e volta, em ms. (modificado de Weschenfelder et al., 2014).

A condução de uma análise sismoestratigráfica no conjunto de dados de sísmica de reflexão de alta frequência $(3,5$ e $7 \mathrm{kHz})$ e resolução do substrato da Lagoa dos Patos permite o reconhecimento de dois importantes sistemas de paleodrenagens na planície costeira média do Rio Grande do Sul. O trecho do perfil de sísmica de reflexão levantando perto do canal da Barra Falsa, na localidade de Bojuru, na margem leste da Lagoa dos Patos, é usado como referência neste artigo (Figuras 1 e 3a).

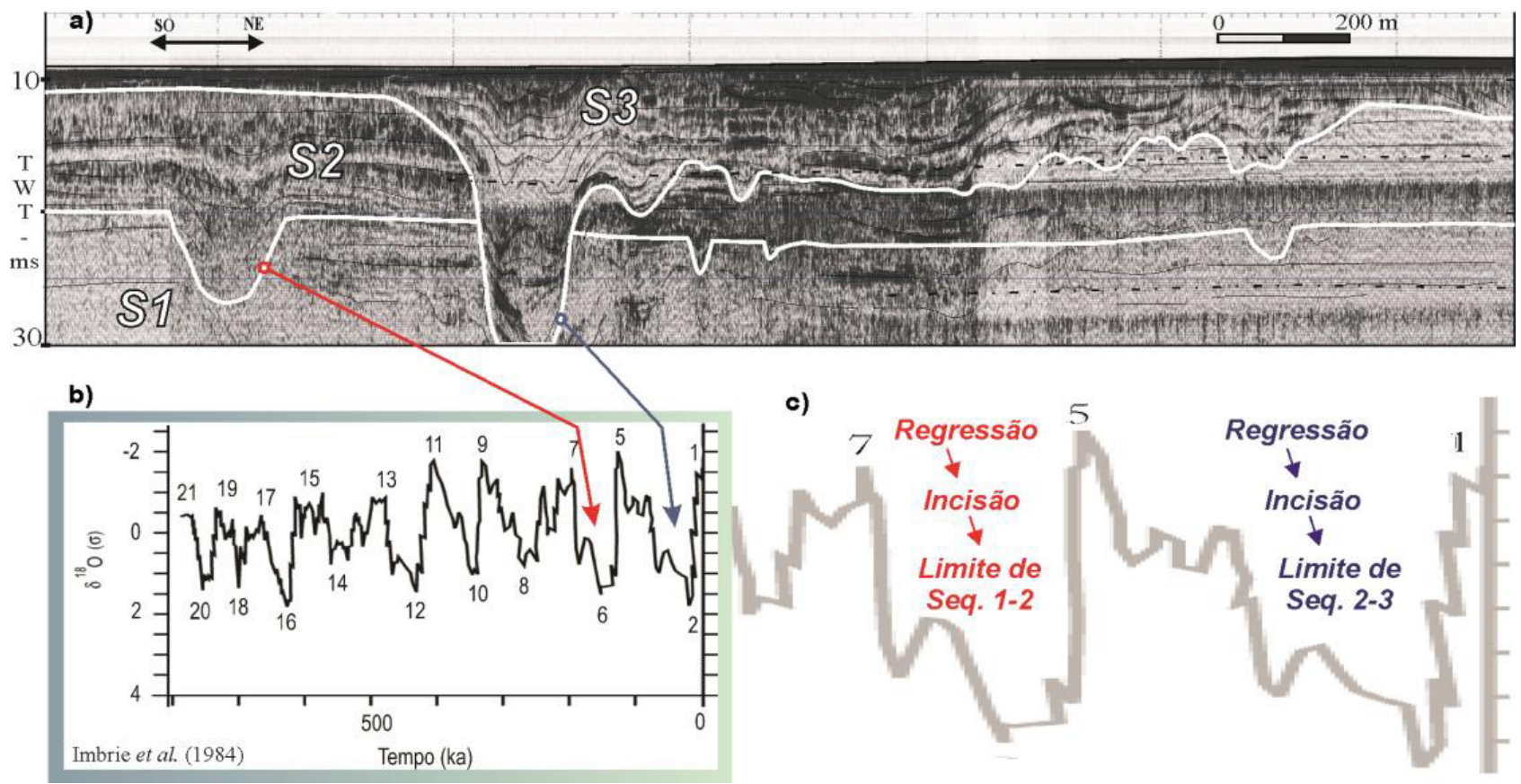

Figura 3. Registro de sísmica de reflexão (trecho do perfil da figura 2) correspondente ao paleocanal do rio Camaquã (profundidade em tempo de ida e volta em $\mathrm{ms}$ ) com respectivo mapeamento das descontinuidades e sequências

A interpretação sísmica revela que os dois sistemas de paleodrenagens, formados em períodos distintos de dissecação do relevo, são delineados por superfícies de descontinuidade sísmica, com boa continuidade lateral, truncando os refletores da sequência sísmica sotoposta. A superfície sísmica delineadora do sistema de paleodrenagens mais antigo é truncada pela superfície que delineia o sistema de paleodrenagens mais jovem (Figura 3a).
Em relação ao sistema de paleocanais mais jovem, os estudos desenvolvidos por Weschenfelder (2005) e Weschenfelder et al. (2005; 2006; 2007; 2008), tendo como base dados de sísmica de reflexão, geocronológicos, sedimentológicos e paleontológicos, indica que o seu preenchimento sedimentar ocorreu no transcorrer do último grande evento transgressivo (final do Pleistoceno) e de mar alto (Holoceno), quando os canais costeiros foram progressivamente afogados e preenchidos por sedimentos fluviais, estuarinos e 
marinhos. Portanto, a sua formação (incisão) pode ser atribuída ao último grande evento regressivo do final do Pleistoceno Superior (18 ka AP), correspondendo ao estágio 2 da curva isotópica do oxigênio de Imbrie et al. (1984) (Figura 3b), quando o nível médio do mar desceu em torno de $120 \mathrm{~m}$ em relação à posição atual na costa sul-brasileira (Corrêa, 1986; 1996; Corrêa et al., 2004).

Um refletor sísmico que marcaria a superfície limite entre o Pleistoceno-Holoceno no interior da Lagoa dos Patos, a uma profundidade média de $12 \mathrm{~m}$, foi mapeado em ecogramas de $7 \mathrm{kHz}$ por Toldo et al. (2000; 2006). Esse refletor corresponde à superfície sísmica que delineia o sistema de paleocanais mais jovens desse artigo.

O canal atual conhecido como Barra Falsa, na localidade de Bojuru, é o remanescente geomorfológico de um antigo canal de ligação entre a Lagoa dos Patos e o oceano Atlântico (Toldo et al., 1991; Weschenfelder et al., 2005; 2008). O paleocanal da Barra Falsa muito provavelmente é o grande canal delineado pelas superfícies sísmicas registradas em um trecho no perfil 2 (Figura 3a). Ele pertence, portanto, ao sistema de paleodrenagens mais jovem aqui definido. A redistribuição sedimentar durante o período de mar alto e início da fase regressiva do Holoceno (5 ka AP) ocasionou o fechamento desses antigos canais de ligação entre a Lagoa dos Patos e o oceano adjacente, restando atualmente somente o canal de ligação (inlet) de Rio Grande, no sul do corpo lagunar.

O sistema de paleocanais mais antigo é truncado pela superfície erosiva formada no evento regressivo do final do Pleistoceno Superior. Desta forma, podem-se posicionar temporalmente os eventos erosivos mapeados pela sísmica no interior da Lagoa dos Patos. Portanto, o processo de formação, incisão, afogamento e posterior preenchimento sedimentar do sistema de paleodrenagens mais antigo pode ser atribuído ao período regressivo-transgressivo imediatamente anterior, correspondendo ao estágio 6 a 5 da curva isotópica do oxigênio de Imbrie et al. (1984) (Figura 3b e 2c ).

No registro sísmico da figura 4 ocorre um sistema de paleovales e paleocanais relacionado ao antigo curso fluvial do rio Jacuí. Observa-se a presença de um forte refletor situado entre 10 e $20 \mathrm{~m}$ de profundidade, o qual marcaria o início de uma deposição flúvio-marinha que ocorreu entre 15 e 75 mil anos AP, sobre as sequencias deposicionais de origem fluvial ocorridas na planície do paleovale do rio Jacuí (S2). A sequência de origem fluvial (S2), apresenta esse refletor mais forte em toplap.
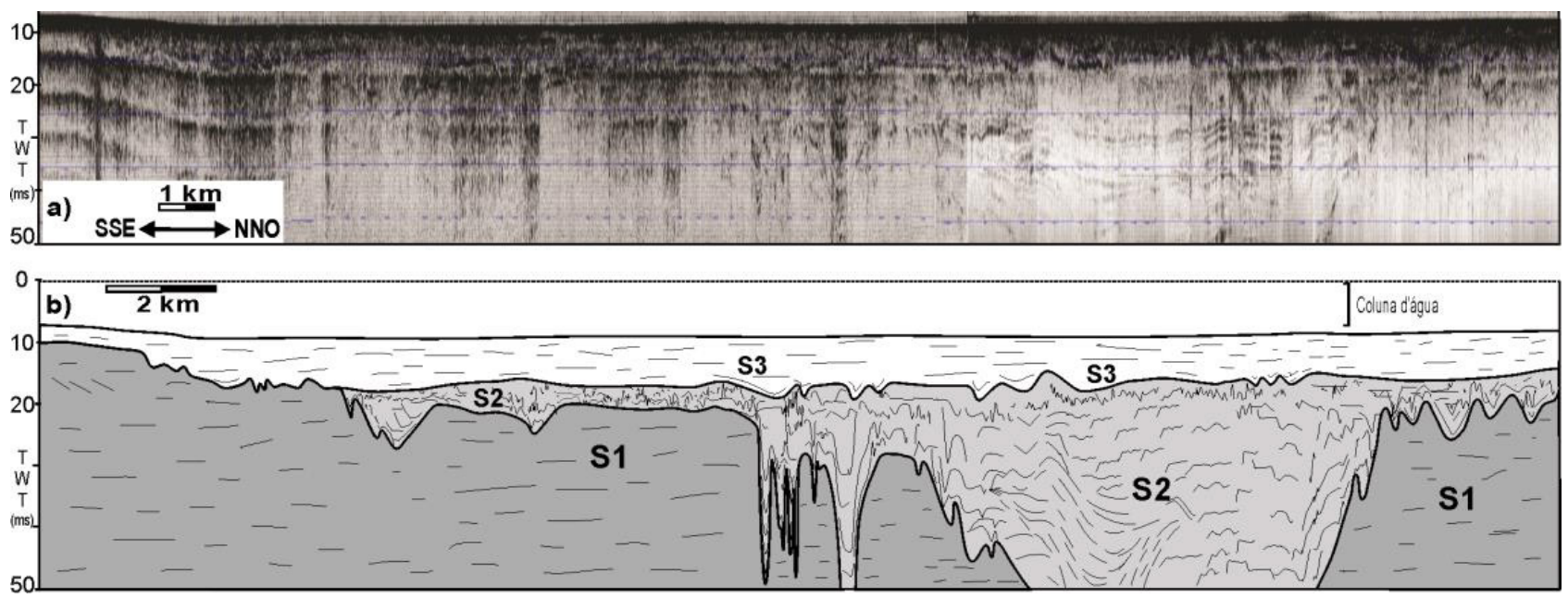

Figura 4 - Registro sísmico de 3,5 kHz com um sistema de paleocanais relacionado ao rio Jacuí (a) e seus respectivos elementos sísmicos e compartimentação em sequências deposicionais S1, S2 e S3 (b). Profundidade em tempo de ida e volta, em ms. (modificado de Weschenfelder et al., 2014).

No perfil sísmico estudado por Weschenfelder et al. (2010a e 2010b), sobre o canal de saída do antigo rio Jacuí, mais ao sul (Figura 5), e também do antigo Camaquã, descrito acima (Figura 2 e 3), os refletores relacionados à deposição fluvial alcançam, também em toplap, o fundo da Lagoa dos Patos, corroborando com a hipótese do fechamento desses canais durante o último evento transgressivo-regressivo. Neste trabalho, o pacote de recobrimento é considerado como de sedimentação flúvio-marinha (S3).
Esta transgressão ocorreu sobre a planície de inundação e dos depósitos de canal do antigo rio Jacuí. Considerando-se a espessura dos depósitos sedimentares observados no perfil da figura 4, o material depositado sobre a planície do antigo rio Jacuí denota um dos maiores (em extensão) e mais longos (em duração) episódios transgressivos. 

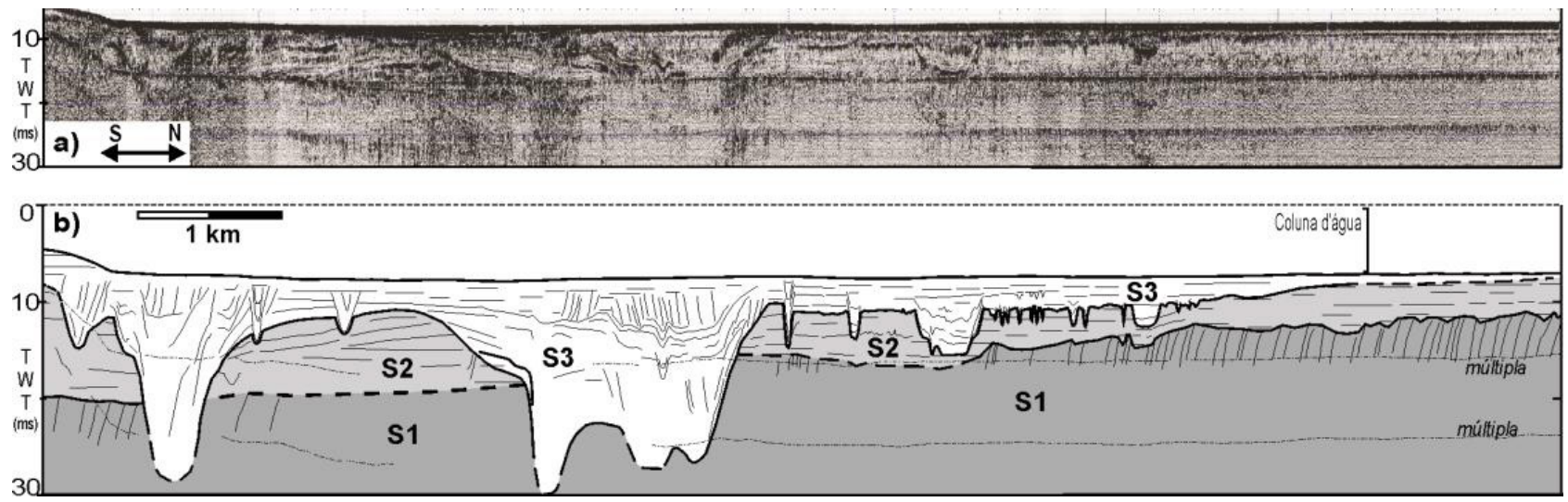

Figura 5 - Paleocanais do rio Jacuí. (a) sem interpretação; (b) interpretado e com as sequências sismodeposicionais; (c) detalhe interpretado com as sequências sismodeposicionais; (d) detalhe não interpretado; (e) detalhe interpretado com as sequências sismodeposicionais e (f) detalhe não interpretado. (modificado de Weschenfelder et al., 2014).

Os depósitos sedimentares da planície costeira do Rio Grande do Sul têm sido relacionados aos quatro últimos grandes eventos transgressivo-regressivos do período Quaternário, responsáveis pela formação de quatro sistemas deposicionais do tipo laguna-barreira (Villwock \& Tomazelli, 1995; Tomazelli \& Villwock, 2000). Esses autores estabeleceram uma correlação entre os períodos de mar alto, a formação dos quatro sistemas deposicionais laguna-barreira da planície costeira do Rio Grande do Sul e os principais picos da curva isotópica do oxigênio de Imbrie et al. (1984).

A formação dos paleocanais é atribuída às regressões marinhas do final do Quaternário, de acordo com as curvas glacio-eustáticas. Recuos do nível do mar expôs a plataforma continental e a borda do talude à incisão fluvial. A região exposta aos processos intempéricos, constituída por sedimentos inconsolidados e suscetíveis a erosões foi recortada por sistemas fluviais que conectaram a bacia de drenagem terrestre aos depocentros da bacia de sedimentação. Durante a condução deste estudo, as descontinuidades sísmicas (erosionais) foram às superfícies balizadoras no estabelecimento dos sistemas de paleodrenagens da zona costeira do Rio Grande do Sul, marcando os limites de sequências sismo-deposicionais.

Os sistemas de drenagens costeiros, vinculados a processos regressivos do nível do mar no final do período Quaternário, provavelmente exerceram um papel importante na arquitetura deposicional, na distribuição das fácies sedimtentares e na disponibilização de espaço de acomodação na borda da bacia sedimentar de Pelotas.

Um mapa de paleodrenagens para a região foi elaborado, posicionando os paleocanais de ligação entre a Lagoa dos Patos e o oceano adjacente, durante as fases transgressivas e regressivas do Quaternário tardio (Figura 6).

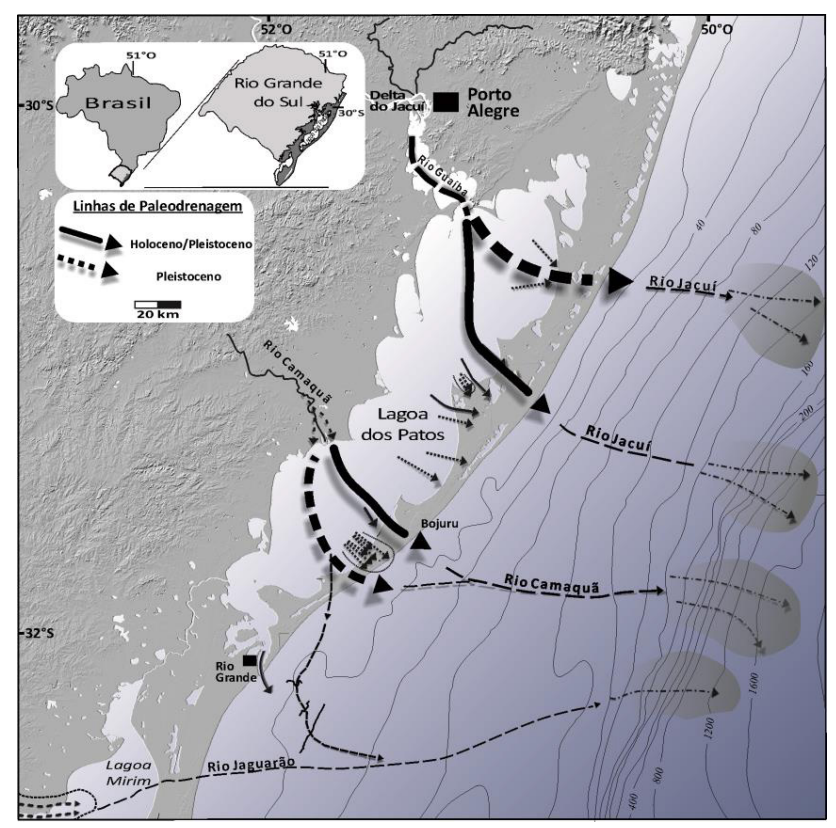

Figura 6 - Sistemas de paleodrenagens da região costeira e plataforma continental do Rio Grande do Sul (modificado de Weschenfelder et al., 2014).

\section{CONCLUSÃO}

A análise sismoestratigráfica em um conjunto de dados de sísmica de reflexão de alta frequência (3,5 e $7 \mathrm{kHz})$ e resolução permitiu o reconhecimento de diversos elementos arquiteturais do substrato da Lagoa dos Patos. Descontinuidades sísmicas marcantes delineiam os limites entre as sequências sismo-deposicionais da zona costeira do Rio Grande do Sul. Os limites dessas sequências são superfícies erosivas formadas por processos vinculados a eventos significativos de rebaixamentos do nível do mar durante o período Quaternário.

Dois sistemas de paleocanais foram reconhecidos no substrato da Lagoa dos Patos: O mais antigo foi 
formado durante o penúltimo grande evento regressivo do Pleistoceno, correspondendo ao pico 6 da curva isotópica do oxigênio. O mais jovem foi formado durante o evento regressivo subsequente, portanto correspondendo ao pico 2 da curva isotópica do oxigênio. O preenchimento sedimentar desses dois sistemas de paleocanais é vinculado aos períodos transgressivos e de mar alto subsequentes aos eventos regressivos respectivos.

As redes de drenagem dissecavam profundamente a planície costeira e a plataforma continental antes da instalação dos eventos transgressivos pós-glaciais subsequentes. Eram sistemas de passagem de fluxo pela plataforma continental exposta pelo evento de regressão forçada, ligando a rede de drenagem continental aos ambientes de deposição na bacia marginal de Pelotas. Os dois paleocanais observados estariam relacionados aos canais fluviais atuais dos rios Jacuí e Camaquã.

\section{AGRADECIMENTOS}

Os autores agradecem o apoio financeiro recebido do CNPq Processos $n^{\circ} 457834 / 2013-7$; n³00609/2013-2 e n³02000/2017-8. O embarque e aquisição sísmica contaram com o apoio do LOG/ FURG e da empresa Geoffshore. Esse trabalho se acha integrado ao Programa de Geologia e Geofísica Marinha - PGGM.

\section{REFERÊNCIAS}

Abreu, J.G.N. \& Calliari, L.J. 2005. Paleocanais da plataforma continental interna do Rio Grande do Sul: evidências de uma drenagem fluvial pretérita. Revista Brasileira de Geofísica, 23(2):123-132.

Corrêa, I.C.S. 1986. Evidence of sea level fluctuation on the Rio Grande do Sul continental shelf, Brazil. Quaternary of South America and Antarctic Peninsula, 40:237-249.

Corrêa, I.C.S. 1996. Les variations du niveau de la mer durant les derniers 17.500 ans BP. L'exemple de la plateforme continentale du Rio Grande do SulBrésil. Marine Geology, 130:163-178.

Corrêa, I.C.S.; Aliotta, S. \& Weschenfelder, J. 2004. Estrutura e evolução dos cordões arenosos pleistocênicos no Canal de Acesso à Laguna dos Patos-RS, Brasil. Pesquisas em Geociências, 31(2):69-78.

Imbrie, J.; Hays, J.D.; Martinson, D.G.; Mclntyre, A.; Mix, A.C.; Morley, J.J.; Pisias, N.G.; Prell, W.L. \& Shackleton, N.J. 1984. The orbital theory of Pleistocene climate: support from a revised chronology of the marine $\delta 180$ record. In: Berger, A.L.; Imbrie, J.; Hays,
J.; Kukla, G. \& Saltzman, B. (eds.). Milankovitch and Climate. Reidel, Boston, 1: 269-305.13

Mitchum Jr., R.M.; Vail, P.R. \& Sangree, J.B. 1977. Seismic stratigraphy and global changes of sea level, Part 6: Stratigraphic interpretation of seismic reflection patterns in depositional sequences. In: Payton, C.E. (ed.). Seismic Stratigraphy: Applications to Hydrocarbon Exploration. AAPG Memoir, 26:117-133.

Toldo Jr, E.E.; Ayup-Zouain, R.N.; Corrêa, I.C.S. \& Dillenburg, S.R. 1991. Barra falsa: hipótese de um paleocanal holocênico de comunicação entre a laguna dos Patos e o Oceano Atlântico. Pesquisas, 18(2):99-103.

Toldo Jr., E.E. 1994. Sedimentação, predição do padrão de ondas e dinâmica sedimentar da antepraia e zona de surfe do sistema lagunar da Lagoa dos Patos. Porto Alegre, 143p. Tese Doutorado, IGEO, UFRGS.

Toldo Jr, E.E.; Dillenburg, S.R.; Corrêa, I.C.S. \& Almeida, L.E.S.B. 2000. Holocene sedimentation in Lagoa dos Patos lagoon, Rio Grande do Sul, Brazil. Journal of Coastal Research, 16(3):816-822.

Toldo Jr, E.E.; Dillenburg, S.R.; Corrêa, I.C.S.; Almeida, L.E.S.B.; Weschenfelder, J. \& Gruber, N.L. 2006. Sedimentação de longo e curto período na Lagoa dos Patos, Sul do Brasil. Pesquisas em Geociências, 33(2):79-86.

Tomazelli, L.J. \& Villwock, J.A. 2000. O Cenozoico no Rio Grande do Sul: Geologia da Planície Costeira, In: Holz, M. \& De Ros, L.F. (eds.). Geologia do Rio Grande do Sul. Pp. 375-406.

Villwock, J.A. \& Tomazelli, L.J., 1995. Geologia costeira do Rio Grande do Sul. Notas Técnicas 8:1-45.

Weschenfelder, J. 2005. Processos sedimentares e variação do nível do mar na região costeira do Rio Grande do Sul, Brasil. Porto Alegre, 141p. Tese de Doutorado em Geociências, Instituto de Geociências, Universidade Federal do Rio Grande do Sul.

Weschenfelder, J.; Corrêa, I.C.S. \& Aliotta, S. 2005. Elementos arquiteturais do substrato da Lagoa dos Patos revelados por sísmica de alta resolução. Pesquisas em Geociências, 32(2): 57-67.

Weschenfelder, J.; Corrêa, I.C.S.; Aliotta, S.; Pereira, C.M. \& Vasconcellos, V.E.B. 2006. Shallow gas accumulation in sediments of the Patos Lagoon, Southern Brazil. Anais da Academia Brasileira de Ciências, 78(3):607-614.

Weschenfelder, J.; Corrêa, I.C.S.; Toldo Jr., E.E. \& Baitelli, R. 2007. Regressões marinhas quaternárias no sul do Brasil indicadas por sistemas de paleodrenagens. In: XII Congresso Latino-Americano de Ciências do Mar - COLACMAR. Boletim de Resumos e CD. 4p.

Weschenfelder, J.; Medeanic, S.; Corrêa, I.C.S. \& Aliotta, S. 2008. Holocene paleo inlet of the Bojuru region, Lagoa dos Patos, southern Brazil. Journal of Coastal Research, 24(1):99-109. 
Braz. J. Aquat. Sci. Technol., 2018, 22(1)

Weschenfelder, J.; Baitelli, R.; Corrêa, I.C.S.; Bortolini, E.C.; dos Santos, C.B., 2014. Quaternary incised valleys in Southern Brazil coastal zone. Journal of South American Earth Sciences, 55:83-93.

\footnotetext{
Submetido: Março/18 Revisado: Maio/18 Aceito:Maio/18 Publicado: Abril/19
} 